TRABAJO FIN DE MÁSTER

MÁSTER DE INVESTIGACIÓN EN ACTIVIDAD FÍSICA Y DEPORTE

ITINERARIO DE SALUD Y CALIDAD DE VIDA

CONVOCATORIA JUNIO 2013

\title{
KINEMATIC ANALYSIS OF BACKWARD AND FORWARD WALKING ON LAND AND IN SHALLOW WATER
}

\author{
Autora: \\ Cristina Cadenas Sánchez
}

Tutores:

Gracia López Contreras

Raúl Arellano Colomina 


\title{
KINEMATIC ANALYSIS OF BACKWARD AND FORWARD WALKING ON LAND AND IN SHALLOW WATER
}

\begin{abstract}
The aim of this study was to compare lower limbs and center of mass kinematics during walking (forward -FW- and backward -BW-) on land and in shallow water. Eight healthy adults (22.12 \pm 1.13 years) performed the protocol to cover a distance of $10 \mathrm{~m}$ at comfortable speed with controlled step frequency. Reflective markers were placed on the lower limbs and digitalized later to obtain kinematics information. In water the values of speed, stride length, step length and support phase were lower whilst those of symmetry of step length were greater $(\mathrm{p}<0.05$ for all) than land conditions. At initial contact (IC), FW in water was associated with more knee and hip flexion compared to on land or at BW. Ankle was more dorsiflexed at BW on land than in water. At final stance (FS), the knee and ankle was more flexed at FW and the hip was more flexed at BW in water. The center of mass (COM) of the hip showed more instability at mediolateral and vertical plane in water than on land. The results suggest that the participants' adaptations to walking in water differ from those in walking on land and provide a starting point for the development and prescription of rehabilitation programs.
\end{abstract}

Keywords: Gait, locomotion, spatiotemporal, biomechanics.

\section{Resumen}

El objetivo de este estudio fue comparar las variables cinemáticas de la marcha (hacia adelante -AD- y hacia atrás-AT-) en el medio terrestre y en el medio acuático. Ocho adultos (22.12 \pm 1.13 años) realizaron el protocolo con el objeto de cubrir una distancia de 10 metros a velocidad confortable y con una frecuencia de paso controlada. Se colocaron marcadores reflectantes en las extremidades inferiores $\mathrm{y}$, posteriormente, se digitalizaron para obtener información cinemática. En agua los valores de la velocidad, longitud de ciclo, longitud de paso y duración de la fase de soporte fueron menores mientras que los de simetría de longitud de paso fueron mayores $(\mathrm{p}<0.05$ para todos) en comparación con el medio terrestre. Al inicio del contacto (IC), la marcha $\mathrm{AD}$ en agua estaba asociada con una mayor flexión de rodilla y cadera en comparación con la marcha en seco o AT. El tobillo tenía una mayor dorsiflexión en la marcha AT en seco que en agua. Al final de la fase de apoyo (FA), la rodilla y el tobillo estaban más flexionados en la marcha $\mathrm{AD}$ y la cadera más flexionada en la marcha AT en el medio acuático. El centro de masas (CM) de la cadera muestra una mayor inestabilidad en el plano mediolateral y vertical en agua que en tierra. Los resultados muestran que las adaptaciones que realizan los participantes en la marcha en el agua difieren de las realizadas en la marcha en el medio terrestre y proporcionan un punto de partida para el desarrollo y la prescripción de programas de rehabilitación.

Palabras clave: marcha, locomoción, espaciotemporal, biomecánica. 


\section{Introduction.}

Human walking, defined as step biped used by the human being to move from one place to another, with minimal effort and minimal energy consumption, is a feature that allows to reveal aspects and individual parameters, health status, self-esteem and emotional situations of each person (1). Consequently, gait is a major sign of independence, quality of life and participation (2) and is frequently impaired by a variety of musculoskeletal and neurological conditions or diseases (for example, osteoarthritis, balance disorders, multiple sclerosis, stroke or cerebral palsy) (3).

Improvement of the walking function is a common goal stated by patients undergoing rehabilitation (3), specifically, it is the number one in patients with stroke (4-8). To improve the locomotion system, exercises are mainly carried out on dry land although now numerous activities have been proposed in the water environment. From a biomechanical point of view, there are two principal reasons why walking in water may be beneficial: the lowering of apparent body weight due to the buoyant force and the increased resistance to movement due to the drag force exerted by water on the human body (9-12).

Regarding normal human locomotion, gait attributes of kinetic, kinematics and spatiotemporal variables are assumed to be symmetrical between lower limbs $(3,13)$. Consequently, a gait asymmetry, which is greater than the normal values, frequently indicates pathology $(13,14)$. Thus, an advantage of this measure is that it provides a reference point to which a specialist may compare the symmetry ratios for a patient population as so to determine if those values represent normal, symmetric or asymmetric gait (3).

Forward walking (FW) may be one of the most common motor tasks in water and land based exercise programs because it can be practiced by any age-group and with most medical conditions $(10,11,15,16)$. On the other hand, other modalities of locomotion like backward walking (BW) are included in some rehabilitation protocols (17) and have gained popularity as an addition to treatment for patients with patellofemoral pain syndrome $(10,18,19)$, anterior cruciate ligament injuries $(10,20)$ or hamstring strain (21), among others.

In the clinical setting, kinematic gait variables are the most common objective measurements performed. In particular, frequency and length of one stride cycle is the most widely reported measure on land based studies, but few authors appear to have investigated the kinematics of backward and forward walking in both conditions (17). 
Recently, Masumoto et al. (2009) reported that the stride frequency was higher and stride length was lower while walking backward in water, compared to walking forward in water. Also, Carneiro et al. (2012) observed that on land walking speed was lower during backward walking compared to forward walking but in shallow water the difference between the walking speeds during BW and FW was not significant. Regarding joint angles, Barela et al. (2006) did not find significant differences in ankle, knee or hip comparing FW kinematics on land and in water. However, Carneiro et al. (2012) explained that BW in water involves more knee and hip flexion than BW on land or FW in either environment. For the symmetry analysis, Kodesh et al. (2012) noted that over-ground gait speed had no significant effects in healthy people.

In summary, gait measurement is essential for understanding the particular deficits exhibited by a patient, guiding clinical decision making, customizing treatment and monitoring the effectiveness of a gait intervention $(3,22)$. For these reasons, a study of the locomotion biomechanics, their exploration and further analysis is an essential tool that reveals the motor possibilities of the subject, spatial, temporal and angular variables that will help us to make a diagnosis, identify the deficiencies of body functional and specific limitations on the gait in order to achieve optimal work programs to benefit the health and quality of life of the subjects. However, to our knowledge, there is a striking lack of information about kinematics and spatiotemporal characteristics of gait when walking forward and backward in water and on land applying three-dimensional motion analysis.

As a result, the biomechanics of movement while walking both on land and in an aquatic environment needs to be better described so that health care professionals have a scientific foundation on which to base their prescriptions of this activity as a therapeutic exercise. The purpose of this study was to compare the spatial and temporal characteristics and joint angles, under four walking conditions: combining two directions (forward and backward) and two environments (land and water). We hypothesize that kinematic variables are different when walking in water compared with walking on land at both directions. 


\section{Methods.}

\subsection{Participants.}

Eight young adults (four males, four females) volunteered to participate in the study. Their mean age, height and body mass values were $22.00 \pm 0.81$ years and 22.25 \pm 1.50 years, $181.6 \pm 0.06 \mathrm{~cm}$ and $168.0 \pm 0.06 \mathrm{~cm}, 73.75 \pm 6.65 \mathrm{~kg}$ and $59.00 \pm 5.77$ $\mathrm{kg}$ for male and female respectively.

Inclusion criteria were age between 20 and 25 years and familiarity with a water pool through aquatic exercise or swimming. On the other hand, exclusion criteria were presenting a neurological o musculoskeletal disorder at the time of the study, presenting a loss of balance or reporting pain in the lower limbs during walking. None subjects presented any impediment and all participants signed consent after being previously informed about the study procedure. The study was approved by the Ethical Committee of the University of Granada (8 January 2013; $n^{\circ} 776$ ).

\subsection{Design and variables.}

This study is a repeated measures design in which each subject performed four levels of the independent variable. To avoid the accumulation of learning effect, the order of application were randomized (counterbalancing technique). We measured the following dependent variables: speed $(\mathrm{m} / \mathrm{s})$, stride length $(\mathrm{m} / \mathrm{cycle})$, step length (m/step), stride duration (s), support phase duration (s and \%), symmetry of step length (arbitrary units), symmetry of step time (arbitrary units), ankle $\left(^{\circ}\right)$, knee $\left(^{\circ}\right)$, hip angle $\left(^{\circ}\right.$ ) and the center of mass of the hip (position (m), displacement (m) and velocity $(\mathrm{m} / \mathrm{s})$ ). As independent variable we had four levels: forward walking on land, backward walking on land, forward walking in water and backward walking in water.

\subsection{Experimental procedure.}

On dry land and in water, the subjects were requested to cover in a randomized order a distance of 10 meters at comfortable speed (controlled by a digital metronome Korg TM-50- at eighty pulses per minute for land and 50 pulses per minute for water condition) employing different modalities: walking forwards (FW) and walking 
backwards (BW). To avoid the interference of the upper limbs, subjects walked forward and backward along a walkway with arms crossed at the chest $(17,23)$.

Twenty-one passive reflective markers were placed on each participant's right and left side at the following points: big toe, first and fifth metatarsal head, calcaneous, lateral malleolus, mid-lateral side of the tibia, femoral epicondyle, mid-side of the thigh, greater trochanter, sacrum and on top of the iliac crest. To obtain the kinematics data in water and dry conditions, participants wore specific running tights adapted to their anthropometric profile on which the markers were placed with hook and loop tapes (Velcro) and in those part where the pant did not cover the body (feet) they were fixed with a black adhesive tape (Farmafix) (Figure 1).

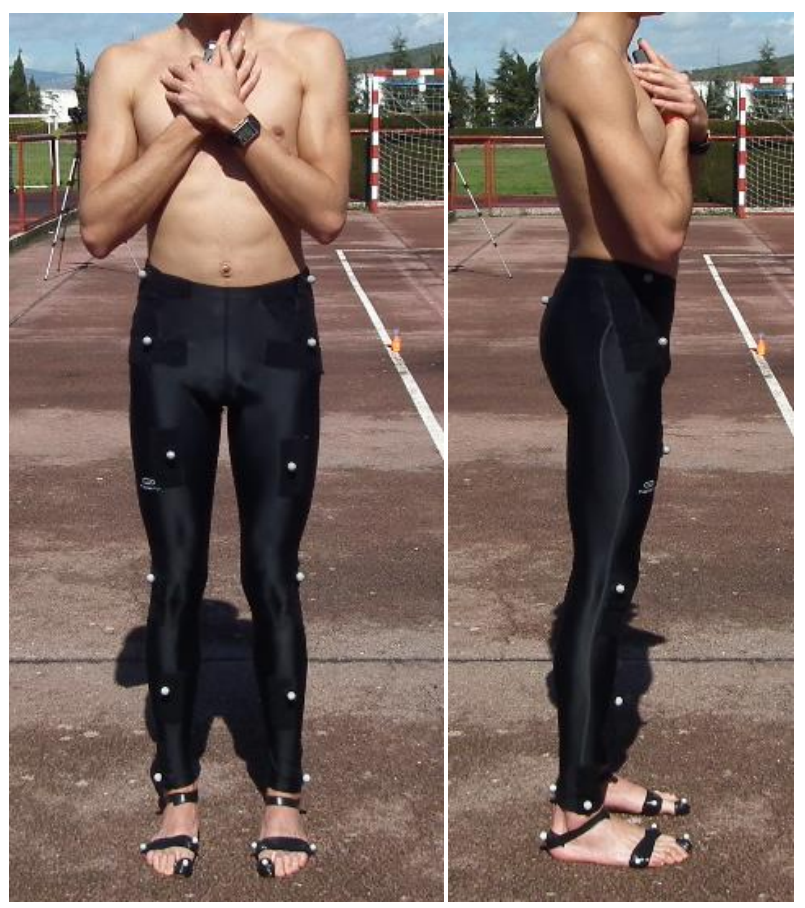

Figure 1. Frontal and lateral view of positions of anatomical markers.

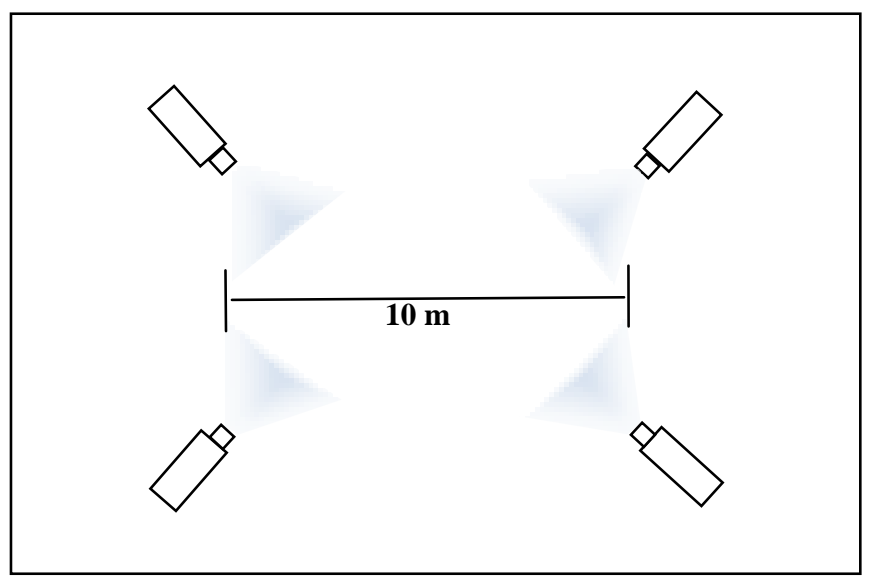

Figure 2. Configuration for camera-based of three-dimensional motion analysis. 
A

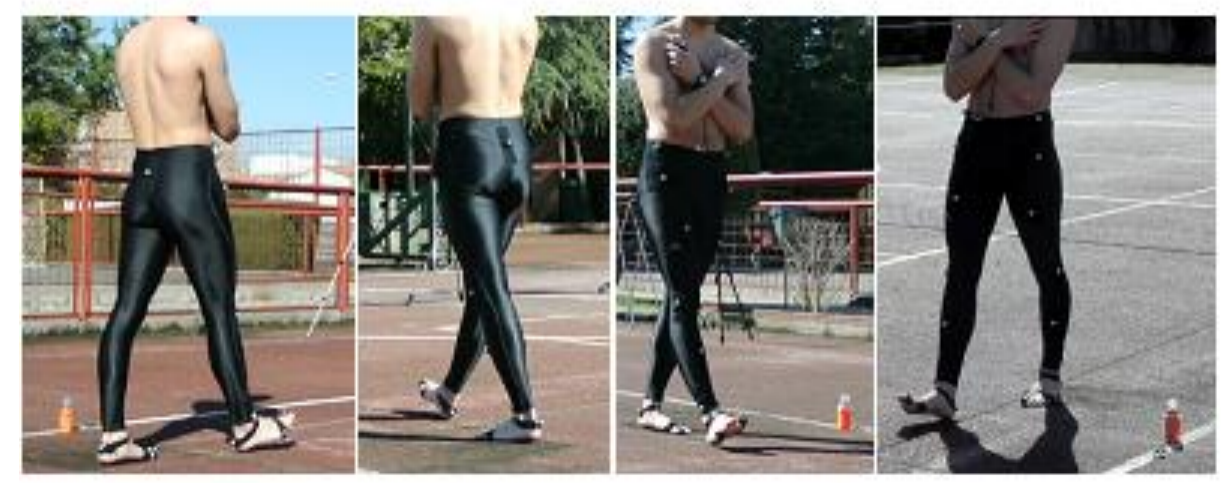

B

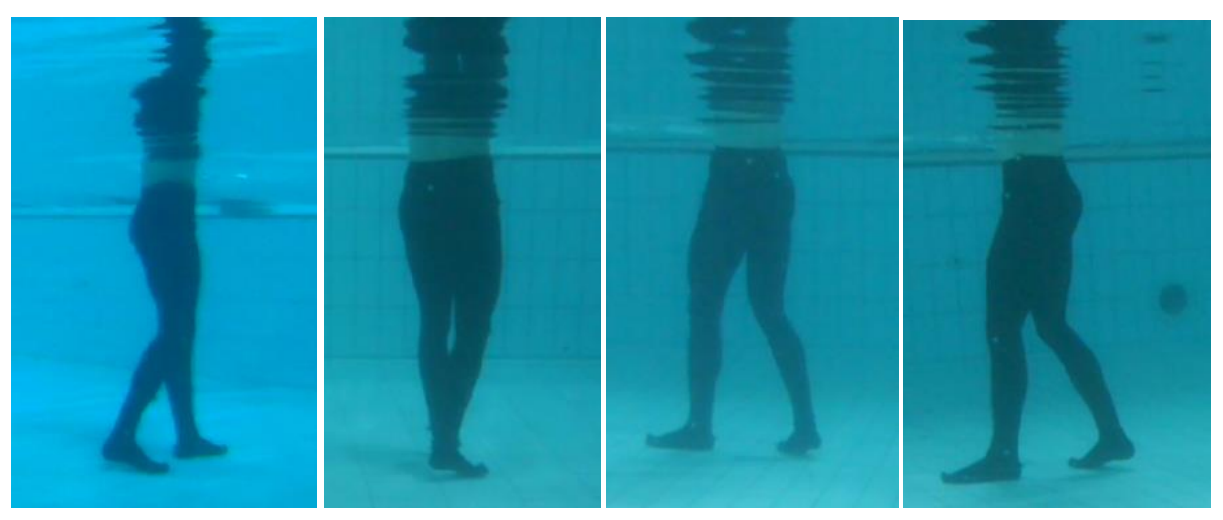

Figure 3. Four planes of digital cameras at forward walking on land (A) and at backward walking in water condition (B). 
Before any measurement, participants performed several trials to familiarize themselves with the instrument (metronome), the modalities of walking and the experimental environment. They were considered adapted when they could maintain their balance and showed coordination between the pulses of metronome and their steps. The number of trial required for the familiarization was between four and six. Data were collected on two different days using the same procedures, due to the venues location. Each subject completed the entire test within a single day. The temperature was set at 24 $\pm 1^{\circ} \mathrm{C}$ on land and $30 \pm 1^{\circ} \mathrm{C}$ in water. Specifically, in water the trials were performed in a swimming pool 10m x 8m and 1, $20 \mathrm{~m}$ deep. Such as depth allowed the subjects to be immersed up approximately at xiphoid process level.

The participant's movement on the sagittal plane (principal plane of movement) was recorded at $60 \mathrm{~Hz}$ (HD 1280x720 and shutter speed 1/1000) with four digital cameras (1J1, Nikon VR 10-30 mm lens) to obtain the measurements (Figure 2 and 3). The video images were synchronized through an external flashing light (about $1 \mathrm{~Hz}$ ). This experimental setup allowed us to perform a standard 3D analysis. We recorded three cycles of gait per modality and the second stride (one gait cycle) was considered for the analysis. The digitalization of all markers, reconstruction, filtering and posterior analysis were performed using the Kwon3D Software (VISOL, Inc.). The real coordinates were reconstructed using a direct linear transformation (DLT) algorithm in the land condition and a localized DLT algorithm to account for refraction in the water condition $(9,24,25)$

\subsection{Data analysis.}

We analyzed one gait stride per trial for each participant for a total of thirty-two strides in each condition. The data were digitally and differentiated using five motion events: initial right heel-strike (RHS), left toe-off (LTO), left heel-strike (LHS), right toe-off (RTO) and the next right heel-strike (RHS2). Among these, RHS is the start event and RHS2 the end event (one cycle). The landmarks were manually digitalized. The original coordinates were filtered using a Butterworth type low-pass filter with a cut-off frequency of $6 \mathrm{~Hz}$ and $2^{\text {nd }}$ order. Each anatomical marker digitalized/filtered allowed us to calculate position, velocity and angle degrees of each segment in three axis: X (mediolateral -rightward-), Y (anteroposterior -forward-) and Z (longitudinal upward-) (Figure 4). All the gait cycles were normalized in time from $0 \%$ to $100 \%$ with 
a step of $1 \%$. Then, these cycles were averaged across trials to obtain the mean cycle for each participant and the same process was repeated to obtain the mean cycle among participants (see figure 6 on results section).
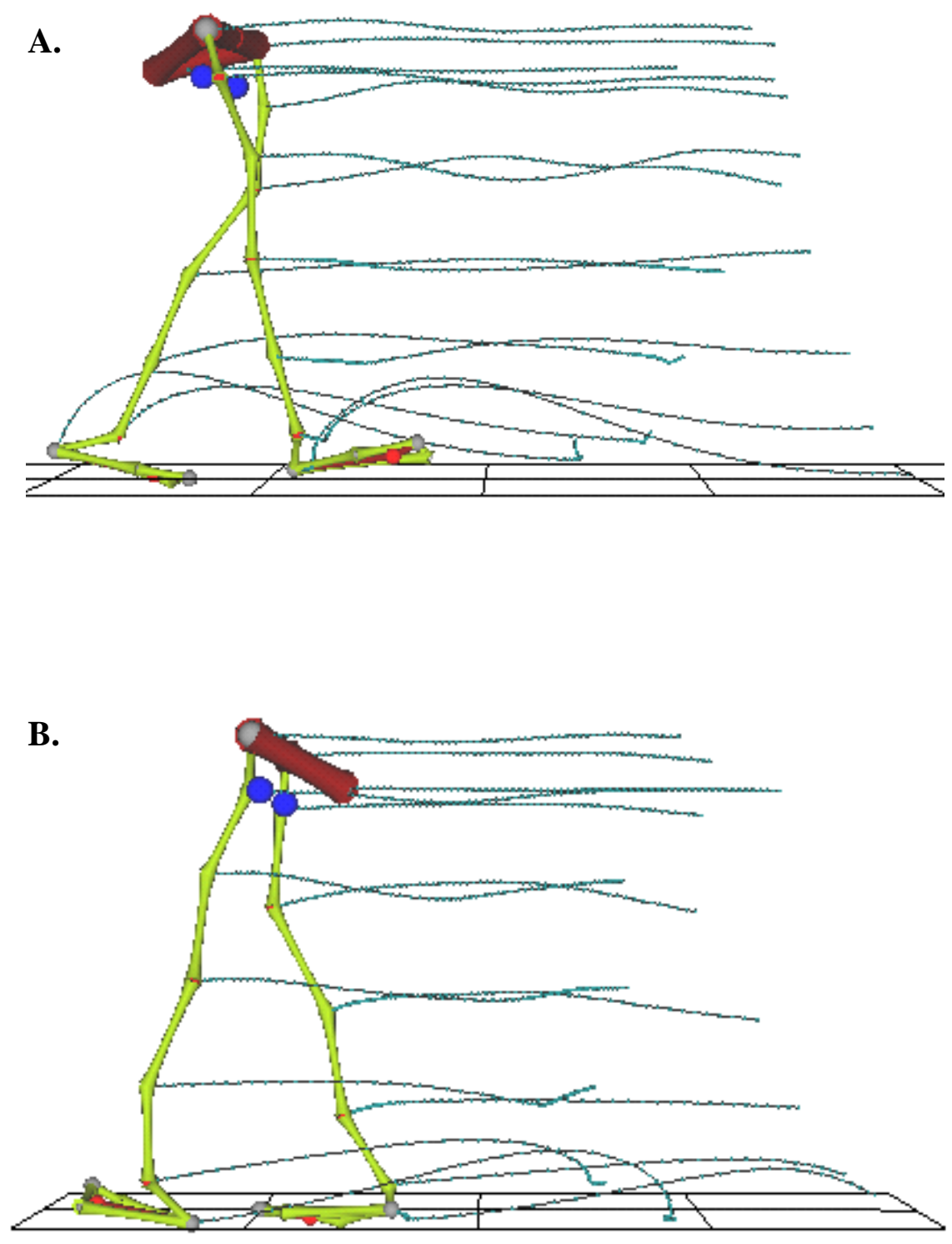

Figure 4. Trajectories of the points in a gait cycle at forward walking (A) and at backward walking (B).

As a result, the following variables were computed: speed (the average speed of the center of mass of the hip), stride length (the distance between two consecutive heel strikes by the same leg), step length (the distance between two consecutive heel strikes), stride duration (the time between two consecutive heel strikes by the same leg), support 
phase duration (the total time the body is supported by one leg during one complete gait cycle), step length symmetry, step time symmetry, displacement of the center of mass of the hip (the average position of the center of mass during the gait cycle in three axes), and ankle, knee and hip joints angles at IC and FS during each stride (Figure 5). Using the same method as Patterson et al. $(2010,2012)$, to calculate the symmetry we used the left and right average values of the steps in a ratio with the largest value in the numerator so that all values for every individual were $>1.0$. A ratio value of 1.0 denotes perfect symmetry. To obtain the angle of ankle joint we took the position of heel and toe in the longitudinal axis ( $\mathrm{Z}$ ) (as defined by the software Kwon 3D) and the position of the ankle and knee in the longitudinal axis $(\mathrm{Z})$ in order to be projected in the $\mathrm{Y}-\mathrm{Z}$ plane. For the angle of the knee joint, we took the position of knee and iliac crest ( $\mathrm{Z}$ axis) and the position of ankle ( $\mathrm{Z}$ axis) to be projected in the sagittal plane (Y-Z). The angle of the hip joint was defined as being formed by the line between the big toe of the foot and the center of mass of the hip in relation to the vertical axis $(Z)$ of the hip's center of mass projected to the $\mathrm{Y}-\mathrm{Z}$ plane (see annex).

A.
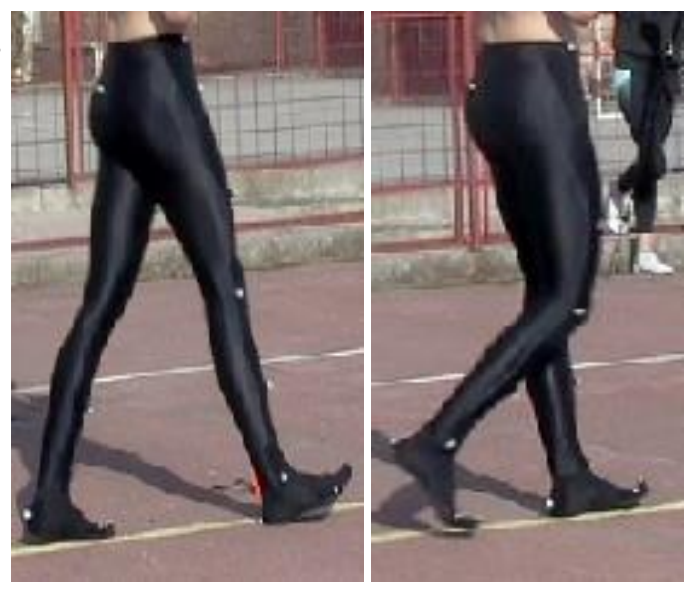

B.

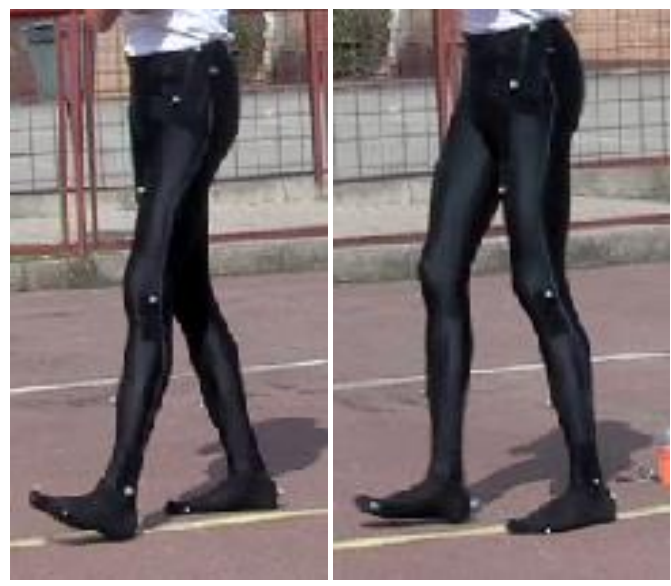

Figure 5. Events related to initial contact (IC) and final stance (FS) respectively during forward (A) and backward walking (B).

Four trials digitized twice by the researcher and twice by an investigator with experience on digitization and management of Kwon3D software, were quantified using intra-class correlation coefficients (ICC) in order to assess the reliability of the digitizing (intra, inter-observer). These correlations were calculated separately for the 
repeated measures of the $\mathrm{X}, \mathrm{Y}$ and $\mathrm{Z}$ coordinate values of the segmental points digitized in several randomized trials. The intra-observer ICC ranged 0.97 (95\% confidence interval (CI) 0.96-0.98) to 0.99 (95\% CI 0.98-0.99); and inter-observer ICC ranged from 0.98 (95\% CI 0.97-0.98) to 0.99 (95\% CI 0.99-0.99). These results showed a high correlation and reliability.

\subsection{Statistical analysis.}

Mean, standard deviation (SD) and confidence interval (CI) were used to represent the average values of the studied variables. The kinematic characteristics of the two environments and directions were compared using repeated measures ANOVA, the factors being environment and direction (thus resulting in the following combinations: forward walking on land, backward walking on land, forward walking in water and backward walking in water). To detect significant differences, post-hoc Bonferroni was applied. The level of significance was set at $\mathrm{p}<0.05$. We assumed the normal distribution of the data. Also, we calculated the coefficient of variation $(\mathrm{CV}, \%)$. This statistical analysis was made using the Medcalc software version 11.5.1 for Windows and verified with SPSS software version 21.0. 


\section{Results.}

All participants were able to walk on land and in water at the xiphoid process level at comfortable speed and in two directions (forward and backward).

\section{Spatiotemporal variables.}

Table 1 presents the mean, SD and CI of the temporal and spatial gait variables. Univariate analyses for spatiotemporal variables indicated differences for speed $F(3,21)=78.94 ; \quad p<0.001$, stride length $F(3,21)=69.30 ; \quad p<0.001 ;$ step length $\mathrm{F}(3,21)=90.34 ; \mathrm{p}<0.001$; stride duration $\mathrm{F}(3,21)=106.96$, $\mathrm{p}<0.001$; support phase duration $F(3,21)=14.16$, $p<0.001$; step length symmetry $F(3,21)=10.59 ; p<0.001$ and symmetry of step time $F(3,21)=3.90, p=0.023$.

Walking speed differed according to the environments $(F(1,7)=131.00$; $\mathrm{p}<0.001)$, directions $(\mathrm{F}(1,7)=111.00 ; \mathrm{p}<0.001)$ and interaction $(\mathrm{F}(1,7)=33.00 ; \mathrm{p}=0.001)$. Bonferroni post hoc analysis showed that on land the speed was greater than in water $(\mathrm{p}<0.001)$ when subjects walking forward $(0.88 \pm 0.02$ and $0.62 \pm 0.01 \mathrm{~m} / \mathrm{s}$ respectively). Specifically, on land, BW $(\mathrm{p}<0.001)$ speed was lower than that for FW $(\mathrm{p}<0.001)$. During in shallow water displacement there were no significant differences between FW and BW speeds ( $\mathrm{p}=0.13)$.

There were significant differences in stride length between environments $(\mathrm{F}(1,7)=75.00 ; \mathrm{p}<0.001)$, directions $(\mathrm{F}(1,7)=128.00 ; \mathrm{p}<0.001)$ and interactions $(\mathrm{F}(1,7)=16.00 ; \mathrm{p}=0.005)$. Stride length was significantly higher in $\mathrm{FW}$ than $\mathrm{BW}$ in the same environments ( $p=0.0005$ for land and $p=0.0007$ for water condition). However, if we compared all conditions, FW and BW were greater in land than in water $(\mathrm{p}<0.001$ for both). Step length differed according environment $(F(1,7)=125.00 ; p<0.001)$, direction $(F(1,7)=97.00 ; p<0.001)$ and interaction $(F(1,7)=37.00 ; p<0.001)$. At $F W$ step length was lower in water $(0.47 \pm 0.01 \mathrm{~m})$ compared to the land condition $(0.66 \pm 0.01$ $\mathrm{m}$ ) and in both environments, FW was greater than BW ( $\mathrm{p}=0.0002$ for the land and $\mathrm{p}=0.001$ for the water condition). 


\section{Table 1}

Mean, standard deviation and confidence interval of kinematic gait variables on dry-land and in water at different direction (forward and backward).

\begin{tabular}{|c|c|c|c|c|c|c|c|c|}
\hline \multirow{3}{*}{ Spatiotemporal } & \multicolumn{4}{|c|}{ Mean \pm SD } & \multicolumn{4}{|c|}{ 95\% Confidence Interval (CI) } \\
\hline & \multicolumn{2}{|c|}{ Dry land } & \multicolumn{2}{|c|}{ Water } & \multicolumn{2}{|c|}{ Dry land } & \multicolumn{2}{|c|}{ Water } \\
\hline & Forward & Backward & Forward & Backward & Forward & Backward & Forward & Backward \\
\hline Speed $(\mathrm{m} / \mathrm{s})$ & $0.88 \pm 0.07^{\mathrm{ab}}$ & $0.58 \pm 0.06^{\mathrm{a}}$ & $0.62 \pm 0.03^{b}$ & $0.55 \pm 0.08$ & $0.82-0.94$ & $0.53-0.63$ & $0.59-0.65$ & $0.48-0.62$ \\
\hline Stride length $(\mathrm{m} /$ cycle $)$ & $1.23 \pm 0.12^{\mathrm{ab}}$ & $0.90 \pm 0.10^{\mathrm{a}}$ & $0.90 \pm 0.08^{\mathrm{ab}}$ & $0.76 \pm 0.07^{\mathrm{a}}$ & $1.13-1.34$ & $0.81-0.99$ & $0.83-0.97$ & $0.70-0.82$ \\
\hline Step length (m/step) & $0.66 \pm 0.05^{\mathrm{ab}}$ & $0.45 \pm 0.04^{\mathrm{a}}$ & $0.47 \pm 0.04^{\mathrm{ab}}$ & $0.39 \pm 0.03^{\mathrm{a}}$ & $0.61-0.70$ & $0.41-0.49$ & $0.43-0.51$ & $0.36-0.42$ \\
\hline Stride duration (s) & $1.40 \pm 0.06^{\mathrm{b}}$ & $1.38 \pm 0.04^{\mathrm{b}}$ & $2.19 \pm 0.19^{b}$ & $1.98 \pm 0.09^{\mathrm{b}}$ & $1.34-1.45$ & $1.34-1.41$ & $2.03-2.36$ & $1.90-2.06$ \\
\hline Support phase duration (\%) & $66.4 \pm 2.12^{\mathrm{b}}$ & $68.8 \pm 3.24^{\mathrm{b}}$ & $60.9 \pm 2.81^{\mathrm{b}}$ & $60.0 \pm 4.06^{\mathrm{b}}$ & $64.6-68.1$ & $66.1-71.5$ & $58.5-63.2$ & $56.6-63.4$ \\
\hline Step length symmetry & $1.02 \pm 0.02^{\mathrm{b}}$ & $1.02 \pm 0.02^{\mathrm{b}}$ & $1.25 \pm 0.17^{\mathrm{b}}$ & $1.22 \pm 0.10^{\mathrm{b}}$ & $1.00-1.04$ & $1.00-1.05$ & $1.11-1.39$ & $1.13-1.31$ \\
\hline Step time symmetry & $1.03 \pm 0.03$ & $1.03 \pm 0.03$ & $1.11 \pm 0.05$ & $1.09 \pm 0.07$ & $1.00-1.06$ & $1.00-1.06$ & $1.06-1.16$ & $1.03-1.16$ \\
\hline
\end{tabular}

${ }^{\text {a }}$ Significant differences for direction.

${ }^{\mathrm{b}}$ Significant differences for environment. 
Significant differences were observed in the stride duration in the different environments $(F(1,7)=514.00 ; p<0.001)$ and interactions $(F(1,7)=8.00 ; p=0.02)$. In water, the duration of the stride cycle was longer than on land for both walking directions $(\mathrm{p}<0.0001$ for $\mathrm{FW}$ and $\mathrm{p}=0.0001$ for $\mathrm{BW})$. The support phase duration differed depending on environment $(\mathrm{F}(1,7)=19.00 ; \mathrm{P}=0.003)$ and direction $(\mathrm{F}(1,7)=1.00$; $\mathrm{p}<0.001)$. Overall, support phase were lower in shallow water for both walking directions, with a decrease between $6 \%$ and $8 \% \quad(\mathrm{FW}, \mathrm{p}=0.01 ; \mathrm{BW}, \mathrm{p}=0.03$ respectively). When we compared the directions in the same condition (land or water), we didn't find any main effect ( $\mathrm{p}=0.21$ for land and $\mathrm{p}=1$ for water).

Regarding to the symmetry, relevant differences were observed in environment $(\mathrm{F}(1,7)=40.00 ; \mathrm{p}<0.01)$, direction $(\mathrm{F}(1,7)=0.00 ; \mathrm{p}<0.01)$ and interaction $(\mathrm{F}(1,7)=0.00$; $\mathrm{p}<0.01)$. In shallow water, pairwise comparison showed lower symmetry than on land at FW ( $\mathrm{p}=0.04)$ and at BW ( $\mathrm{p}=0.006)$. On the other hand, for the step time symmetry there was no significant difference.

\section{Joint Angles.}

Figure 6 depicts the mean and SD of stride cycle and Table 2 shows mean $( \pm$ $\mathrm{SD}), \mathrm{CI}$ and $\mathrm{CV}$ at initial contact and final stance of ankle, knee, and hip joint angle patterns of all participants walking forward and backward on land and in water. Univariate analyses for angle variables indicated differences for ankle joint at IC $\mathrm{F}(3,21)=109.49, \mathrm{p}<0.001$ and at $\mathrm{FS} F(3,21)=47.79, \mathrm{p}<0.001$; knee joint at IC $\mathrm{F}(3,21)=13.78, \mathrm{p}<0.001$ and at $\mathrm{FS} F(3,21)=158.65, \mathrm{p}<0.001$; and hip joint at IC $\mathrm{F}(3,21)=286.70, \mathrm{p}<0.001$ and at $\mathrm{FS} F(3,21)=51.83, \mathrm{P}<0.001$.

Qualitatively (see figure 6.1), the ankle, in forward walking, was more flexed on land during the support phase (first $60 \%$ of the cycle gait approximately) and in water during the swing phase (the last $40 \%$ of stride cycle approximately). The patterns on backward walking were different between conditions because the ankle was more extended in water than on land. For the knee joint all modalities seemed to have roughly similar patterns in both conditions (see figure 6.2.) In forward walking the hip angle was lower on land during the $60 \%$ of the cycle and greater in the swing phase. In backward walking we showed that the patterns are very similar in about $45 \%$ of the cycle, between this percentage and $70 \%$ the hip was lower on land than in water, and the remaining $30 \%$ of the stride cycle the hip angle increased on land compared to the water condition (see figure 6.3). 

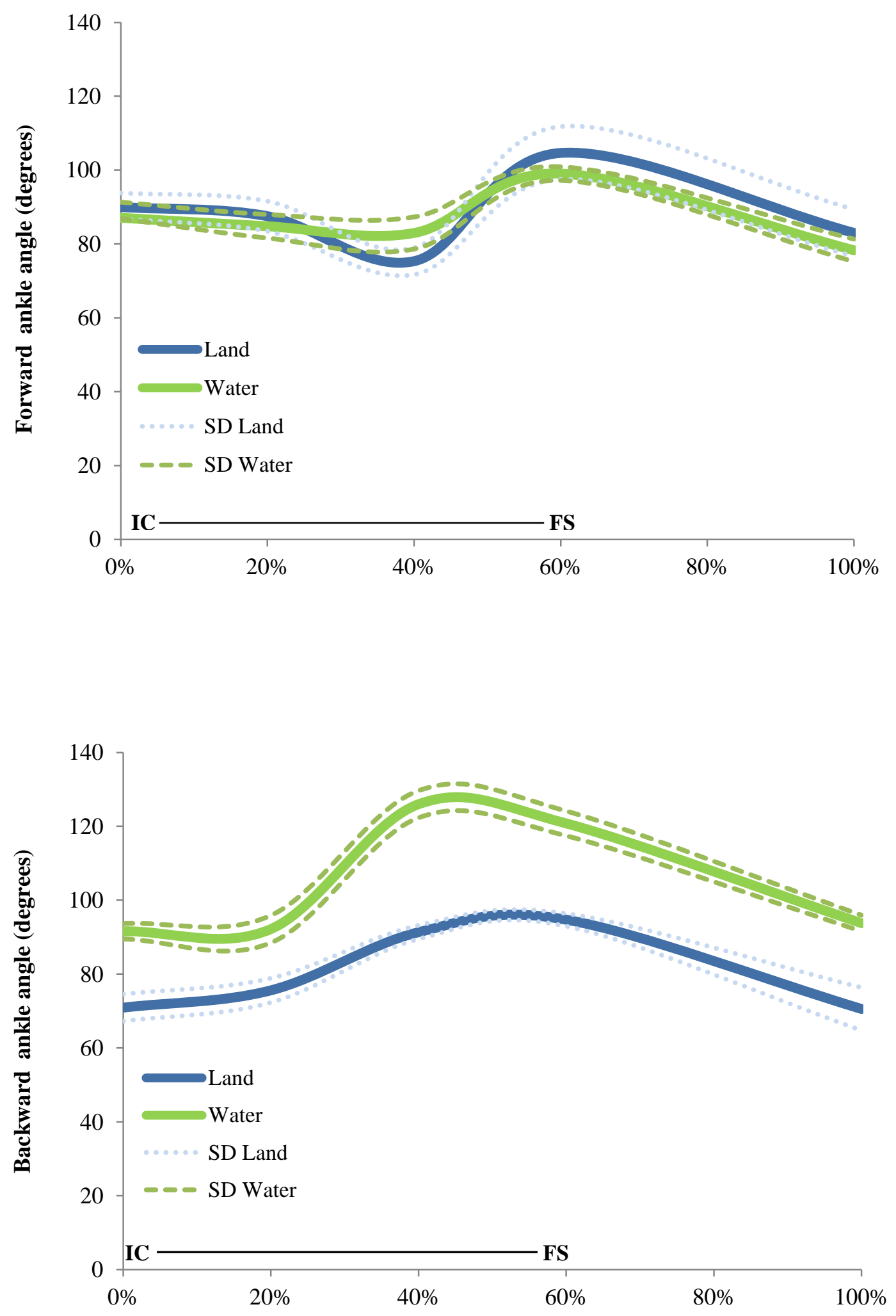

Figure 6.1. Mean and standard deviation for ankle angle in a gait cycle. Walking forward (first line) and backward (second line) in the two environments. Discontinuous dashed line represents the standard deviation variability point by point on land and discontinuous points in water. Horizontal lines indicate the moment between initial contact (IC) and final stance (FS) of the right limb. All data are normalized $(\mathrm{n}=8)$. 

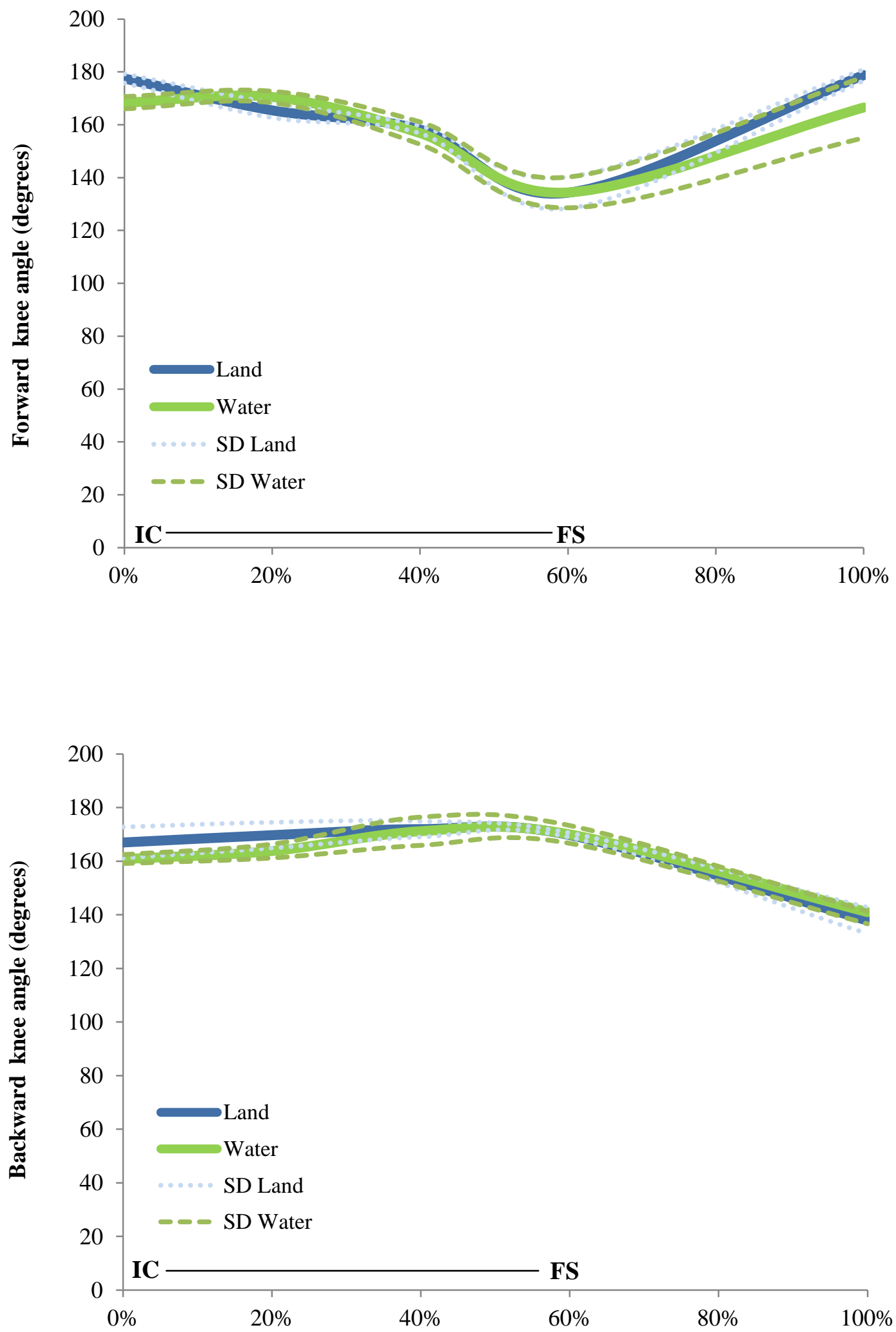

Figure 6.2. Mean and standard deviation for knee angle in a gait cycle. Walking forward (first line) and backward (second line) in the two environments. Discontinuous dashed line represents the standard deviation variability point by point on land and discontinuous points in water. Horizontal lines indicate the moment between initial contact (IC) and final stance (FS) of the right limb. All data are normalized $(n=8)$. 

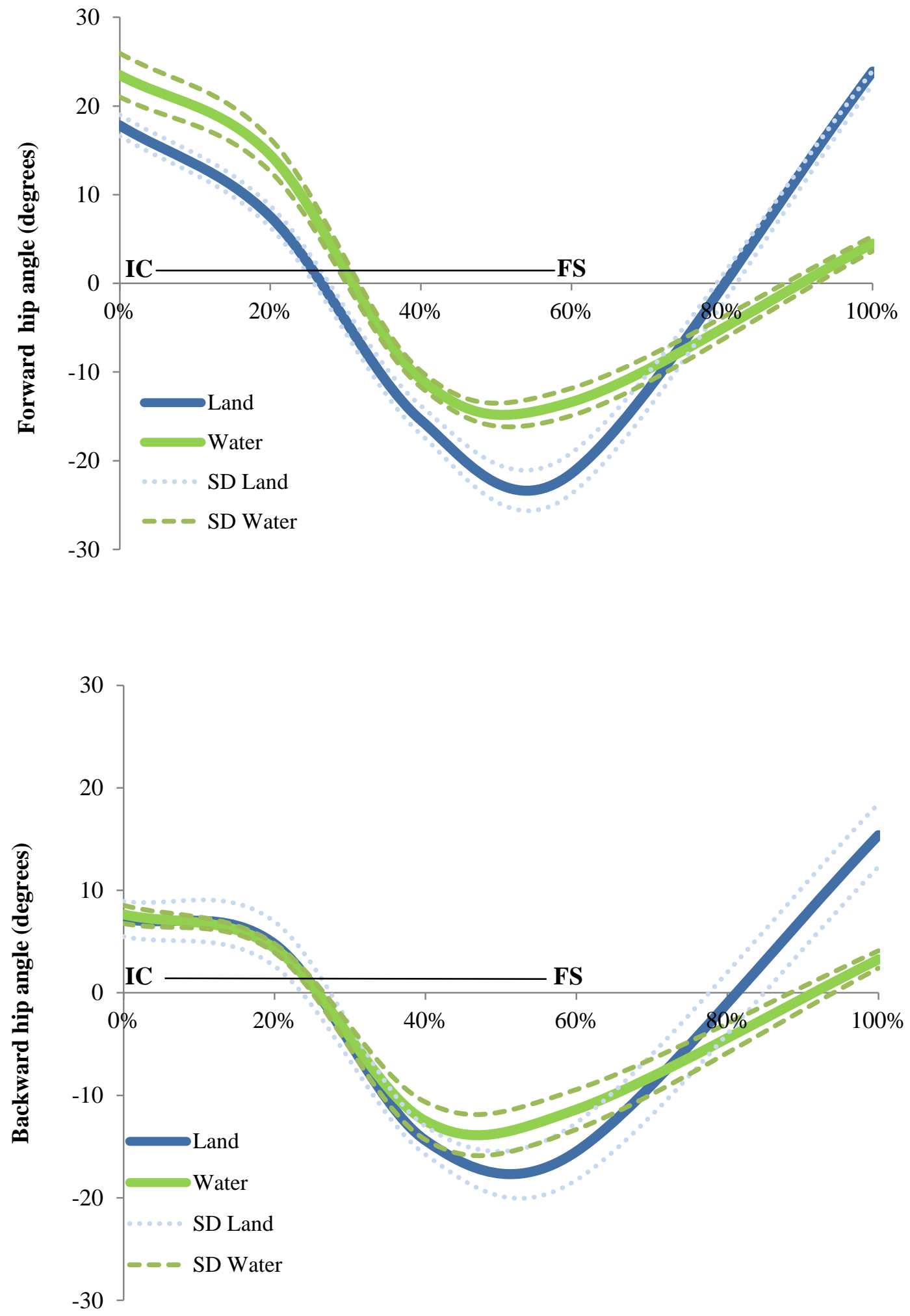

Figure 6.3. Mean and standard deviation for hip angle in a gait cycle. Walking forward (first line) and backward (second line) in the two environments. Discontinuous dashed line represents the standard deviation variability point by point on land and discontinuous points in water. Horizontal lines indicate the moment between initial contact (IC) and final stance (FS) of the right limb. All data are normalized $(n=8)$. 


\section{Table 2}

Mean, standard deviation and confidence interval of angular values at initial contact (IC) and final stance (FS) in forward and backward direction on dry land and in water.

\begin{tabular}{|c|c|c|c|c|c|c|c|c|}
\hline \multirow{3}{*}{$\begin{array}{l}\text { Joint } \\
\text { angle }\end{array}$} & \multicolumn{4}{|c|}{ Mean \pm SD } & \multicolumn{4}{|c|}{$\begin{array}{l}95 \% \text { Confidence Interval (CI) } \\
\text { Coefficient of variation }(\mathrm{CV})\end{array}$} \\
\hline & \multicolumn{2}{|c|}{ Dry land } & \multicolumn{2}{|c|}{ Water } & \multicolumn{2}{|c|}{ Dry land } & \multicolumn{2}{|c|}{ Water } \\
\hline & Forward & Backward & Forward & Backward & Forward & Backward & Forward & Backward \\
\hline Ankle $\left(^{\circ}\right)$ & $90.0 \pm 2.95^{\mathrm{a}}$ & $71.1 \pm 3.15^{\mathrm{ab}}$ & $87.0 \pm 3.33$ & $91.6 \pm 1.59^{\mathrm{b}}$ & $\begin{array}{l}87.6-92.5 \\
3.27 \%\end{array}$ & $\begin{array}{l}68.5-73.8 \\
4.43 \%\end{array}$ & $\begin{array}{l}84.3-89.8 \\
3.82 \%\end{array}$ & $\begin{array}{l}90.2-92.9 \\
1.74 \%\end{array}$ \\
\hline Knee $\left(^{\circ}\right)$ & $178.0 \pm 1.59^{\mathrm{ab}}$ & $166.1 \pm 4.7^{\mathrm{a}}$ & $168.1 \pm 7.1^{b}$ & $161.2 \pm 4.9$ & $\begin{array}{c}176.7-179.3 \\
0.89 \%\end{array}$ & $\begin{array}{c}162.1-170.0 \\
2.83 \%\end{array}$ & $\begin{array}{c}162.1-174.0 \\
4.22 \%\end{array}$ & $\begin{array}{c}157.0-165.4 \\
3.08 \%\end{array}$ \\
\hline $\operatorname{Hip}\left({ }^{\circ}\right)$ & $17.4 \pm 1.05^{\mathrm{ab}}$ & $7.0 \pm 1.33^{\mathrm{a}}$ & $23.5 \pm 2.02^{\mathrm{ab}}$ & $7.6 \pm 0.79^{\mathrm{a}}$ & $\begin{array}{c}16.5-18.3 \\
6.03 \%\end{array}$ & $\begin{array}{l}5.9-8.1 \\
18.93 \%\end{array}$ & $\begin{array}{l}21.8-25.2 \\
8.58 \%\end{array}$ & $\begin{array}{l}7.0-8.3 \\
10.39 \%\end{array}$ \\
\hline At FS & & & & & & & & \\
\hline Ankle $\left(^{\circ}\right)$ & $101.6 \pm 6.82$ & $95.7 \pm 2.16^{\mathrm{b}}$ & $99.1 \pm 1.79^{\mathrm{a}}$ & $119.2 \pm 3.88^{\mathrm{ab}}$ & $\begin{array}{c}95.9-107.3 \\
6.71 \%\end{array}$ & $\begin{array}{c}93.9-97.5 \\
2.26 \%\end{array}$ & $\begin{array}{c}97.6-100.6 \\
1.80 \%\end{array}$ & $\begin{array}{c}116.0-122.4 \\
3.25 \%\end{array}$ \\
\hline Knee $\left(^{\circ}\right)$ & $135.0 \pm 4.90^{\mathrm{a}}$ & $170.2 \pm 1.03^{\mathrm{a}}$ & $131.1 \pm 6.66^{\mathrm{a}}$ & $169.0 \pm 2.97^{\mathrm{a}}$ & $\begin{array}{c}130.9-139.1 \\
3.63 \%\end{array}$ & $\begin{array}{c}169.3-171.0 \\
0.60 \%\end{array}$ & $\begin{array}{c}125.5-136.6 \\
5.08 \%\end{array}$ & $\begin{array}{c}166.5-171.4 \\
1.76 \%\end{array}$ \\
\hline $\operatorname{Hip}\left({ }^{\circ}\right)$ & $-21.3 \pm 1.77^{\mathrm{ab}}$ & $-15.2 \pm 2.18^{\mathrm{ab}}$ & $-13.2 \pm 1.24^{\mathrm{ab}}$ & $-11.3 \pm 1.57^{\mathrm{ab}}$ & $\begin{array}{l}-22.8--19.9 \\
-8.28 \%\end{array}$ & $\begin{array}{c}-17.0--13.4 \\
-14.34 \%\end{array}$ & $\begin{array}{c}-14.3--12.2 \\
-9.40 \%\end{array}$ & $\begin{array}{c}-12.6--9.9 \\
-13.92 \%\end{array}$ \\
\hline
\end{tabular}

${ }^{\text {a }}$ Significant differences for direction.

${ }^{\mathrm{b}}$ Significant differences for environment. 
We analyzed separately the ankle, knee and hip degree at initial contact (IC) and final stance (FS) in all conditions. For ankle joint, effects differed between environment $(\mathrm{F}(1,7)=61.0, \mathrm{p}<0.001 ; \mathrm{F}(1,7)=89.00, \mathrm{p}<0.001)$, direction $(\mathrm{F}(1,7)=70.00, \mathrm{p}<0.001$; $\mathrm{F}(1,7)=24.00, \mathrm{p}=0.002)$ and interaction $(\mathrm{F}(1,7)=307.0, \mathrm{p}<0.001 ; \mathrm{F}(1,7)=46.00, \mathrm{p}<0.001)$ at IC and FS respectively. At IC, ankle angle showed a greater dorsiflexion during BW on land than BW in water $(\mathrm{p}<0.0001)$ and was also more flexed in $\mathrm{BW}$ than FW on land $(\mathrm{p}<0.0001)$. At FS, the ankle was more dorsiflexed during BW on land than in water $(p<0.0001)$, and in the aquatic environment at FW compared to BW $(p<0.0001)$.

For the knee angle, differences were observed between environment $(\mathrm{F}(1,7)=49.00, \quad \mathrm{p}<0.001 ; \quad \mathrm{F}(1,7)=1, \quad \mathrm{p}<0.001)$, direction $\quad(\mathrm{F}(1,7)=28.00 ; \quad \mathrm{p}=0.001 ;$ $\mathrm{F}(1,7)=372.00, \mathrm{p}<0.001)$ and interaction $(\mathrm{F}(1,7)=0.00, \mathrm{p}<0.001 ; \mathrm{F}(1,7)=1.00, \mathrm{p}<0.001)$ at IC and FS respectively. At IC of the gait cycle, the knee was more flexed during FW in water than FW on land $(p=0.04)$ and at BW compared to FW on land $(p=0.002)$. At FS, knee angle at FW was more flexed than BW both in water and on land $(\mathrm{p}<0.0001)$.

The results of the hip angle differed between environment $(F(1,7)=47.00$, $\mathrm{p}<0.001 ; \mathrm{F}(1,7)=112.05, \mathrm{p}<0.001)$, direction $(\mathrm{F}(1,7)=550.00 ; \mathrm{p}<0.001 ; \mathrm{F}(1,7)=51.00$, $\mathrm{p}<0.001)$ and interaction $(\mathrm{F}(1,7)=66.00, \mathrm{p}<0.001 ; \mathrm{F}(1,7)=9.00, \mathrm{p}<0.018)$ at IC and FS. Bonferroni post hoc explained that, at IC, the hip was more flexed in forward walking in water than on land $(\mathrm{p}=0.0005)$. Moreover, we found significant differences between directions in the same environment. As a result, in both conditions FW was more flexed than BW ( $<<0.0001)$. At FS, the hip angle was more flexed in water than on land $(\mathrm{p}<0.05)$, and BW compared to FW was more flexed as well $(\mathrm{p}<0.01)$.

\section{Center of mass (COM) displacement.}

Table 3 presents the mean $( \pm \mathrm{SD})$ values and the Confidence Interval $(\mathrm{CI})$ of the center of mass in three axes (X, Y and Z). Figure 7.1, 7.2 and 7.3 depicts the mean and standard deviation of COM displacement in a stride cycle. Univariate analyses for the center of mass indicated differences for the $\mathrm{X}$ axis $\mathrm{F}(3,21)=170.44 ; \mathrm{p}<0.001$, $\mathrm{Y}$ axis $\mathrm{F}(3,21)=312.77 ; \mathrm{p}<0.001$ and $\mathrm{Z}$ axis $\mathrm{F}(3,21)=35.12 ; \mathrm{p}<0.001$.

The $X$ axis differed according to the environment $(F(1,7)=267.00 ; p<0.001)$, direction $(\mathrm{F}(1,7)=78.00 \mathrm{p}<0.001)$ and interaction $(\mathrm{F}(1,7)=60.00 ; \mathrm{p}=0.001)$. Bonferroni post hoc analysis showed that on land the mediolateral COM displacement decreased in both directions compared to in water $(\mathrm{p}<0.001)$. At FW in water, the mediolateral COM 
displacement was greater than $\mathrm{BW}(\mathrm{p}=0.0002)$. There were no significant differences between FW and BW on land $(\mathrm{p}=0.15)$.

For the $\mathrm{Y}$ axis, the values differed between environment $(\mathrm{F}(1,7)=248.00$, $\mathrm{p}<0.001)$, direction $(\mathrm{F}(1,7)=970.00, \mathrm{p}<0.001)$ and interaction $(\mathrm{F}(1,7)=47.00, \mathrm{p}<0.001)$. Pairwise comparison showed that at $\mathrm{FW}$ and $\mathrm{BW}$ anteroposterior $\mathrm{COM}$ displacement was lower in water than on land $(\mathrm{p}<0.001)$. At the same environment, anteroposterior COM displacement decreased at BW compared to FW ( $\mathrm{p}<0.001)$.

$\mathrm{Z}$ axis differed between environment $(\mathrm{F}(1,7)=76.00, \mathrm{p}<0.001)$, direction $(F(1,7)=0.00, p<0.001)$ and interaction $(F(1,7)=0.00, p<0.001)$. Vertical COM excursion was greater in water in either direction compared to on land. We didn't find significant differences between FW and BW at the same environment $(\mathrm{p}=1)$. 


\section{Table 3}

Mean, standard deviation and confidence interval of $\mathrm{X}, \mathrm{Y}$ and $\mathrm{Z}$ axes in forward and backward direction on dry land and in water.

\begin{tabular}{|c|c|c|c|c|c|c|c|c|}
\hline \multirow{3}{*}{ Axes } & \multicolumn{4}{|c|}{ Mean \pm SD } & \multicolumn{4}{|c|}{ 95\% Confidence Interval (CI) } \\
\hline & \multicolumn{2}{|c|}{ Dry land } & \multicolumn{2}{|c|}{ Water } & \multicolumn{2}{|c|}{ Dry land } & \multicolumn{2}{|c|}{ Water } \\
\hline & Forward & Backward & Forward & Backward & Forward & Backward & Forward & Backward \\
\hline $\mathrm{X}(\mathrm{m})$ & $1.22 \pm 0.01^{b}$ & $1.20 \pm 0.01^{\mathrm{b}}$ & $1.41 \pm 0.02^{\mathrm{ab}}$ & $1.30 \pm 0.02^{\mathrm{ab}}$ & $1.20-1.23$ & $1.19-1.21$ & $1.39-1.43$ & $1.28-1.32$ \\
\hline $\mathrm{Y}(\mathrm{m})$ & $2.43 \pm 0.06^{\mathrm{ab}}$ & $1.80 \pm 0.06^{\mathrm{ab}}$ & $1.82 \pm 0.07^{\mathrm{ab}}$ & $1.47 \pm 0.02^{\mathrm{ab}}$ & $2.37-2.48$ & $1.75-1.85$ & $1.75-1.88$ & $1.44-1.49$ \\
\hline $\mathrm{Z}(\mathrm{m})$ & $1.00 \pm 0.02^{\mathrm{b}}$ & $1.00 \pm 0.02^{\mathrm{b}}$ & $1.10 \pm 0.02^{\mathrm{b}}$ & $1.09 \pm 0.02^{\mathrm{b}}$ & $0.98-1.02$ & $0.98-1.02$ & $1.08-1.11$ & $1.07-1.11$ \\
\hline
\end{tabular}

${ }^{a}$ Significant differences for direction.

${ }^{\mathrm{b}}$ Significant differences for environment. 

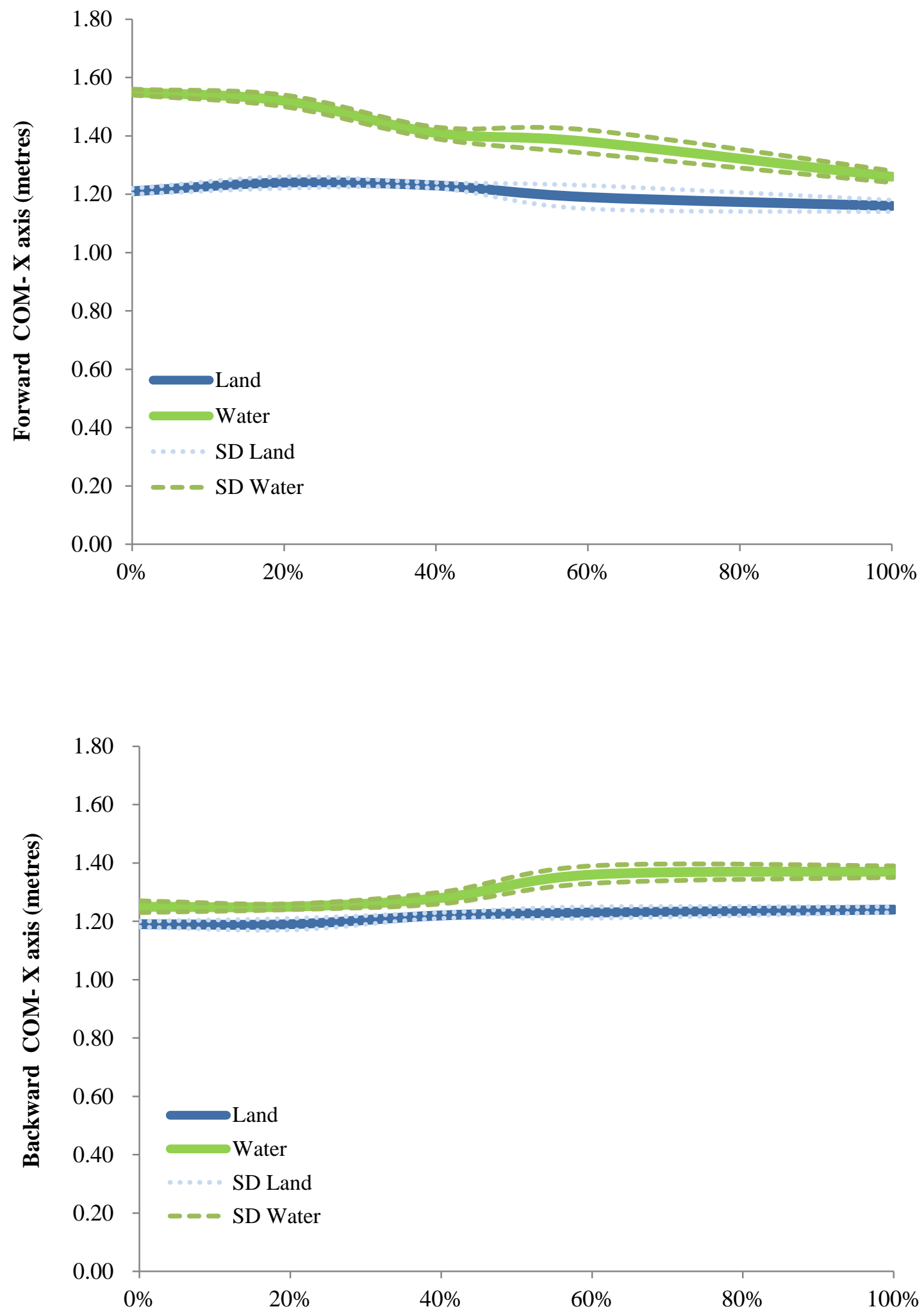

Figure 7.1. Mean and standard deviation of center of mass in $\mathrm{X}$ axis in a gait cycle. Walking forward (first line) and backward (second line) in the two environments. Discontinuous dashed lines represent the standard deviation variability point by point on land and discontinuous points in water. All data are normalized $(n=8)$. 

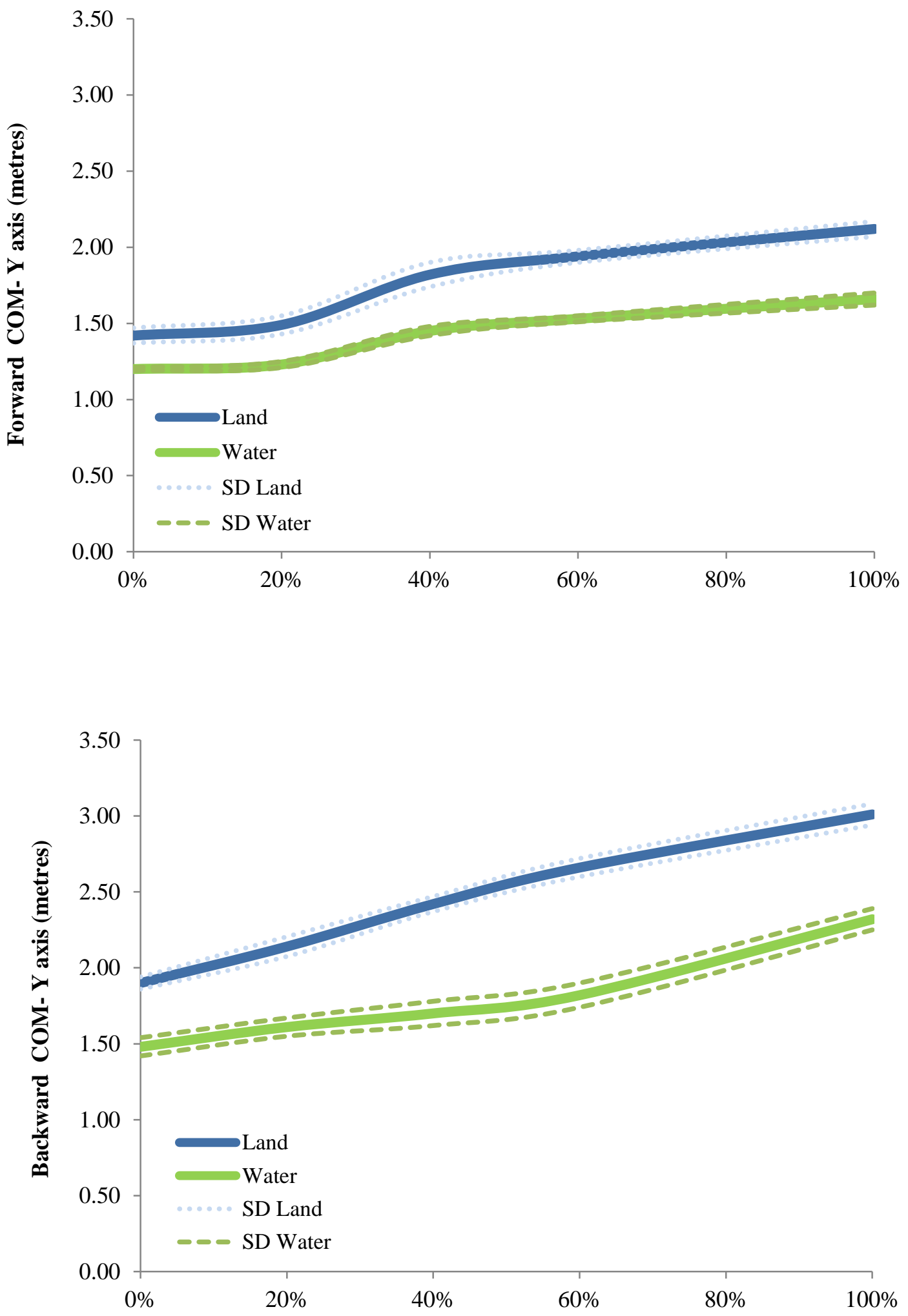

Figure 7.2. Mean and standard deviation of center of mass in $\mathrm{Y}$ axis in a gait cycle. Walking forward (first line) and backward (second line) in the two environments. Discontinuous dashed lines represent the standard deviation variability point by point on land and discontinuous points in water. All data are normalized $(n=8)$. 

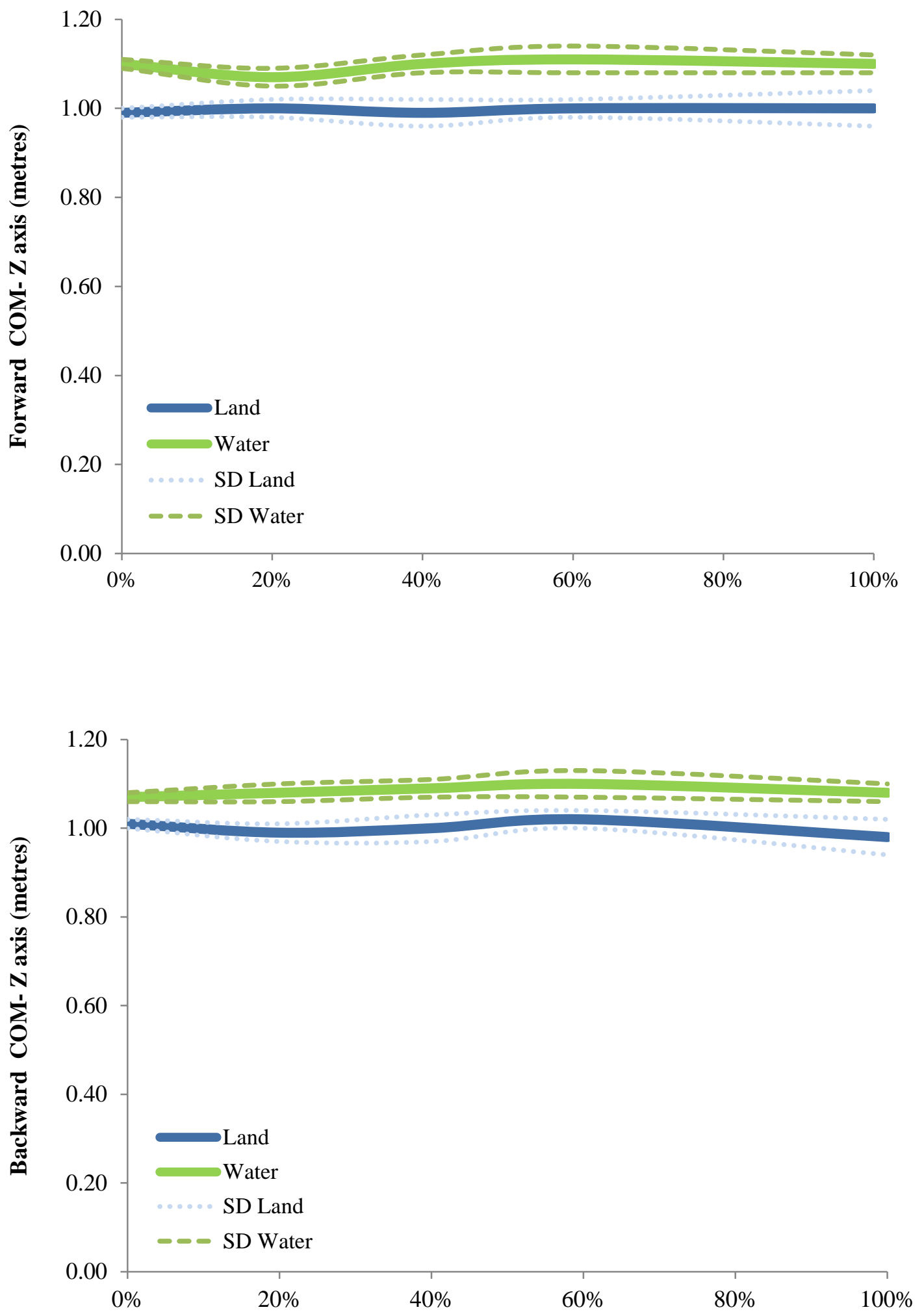

Figure 7.3. Mean and standard deviation of center of mass in $\mathrm{Z}$ axis in a gait cycle. Walking forward (first line) and backward (second line) in the two environments. Discontinuous dashed lines represent the standard deviation variability point by point on land and discontinuous points in water. All data are normalized $(n=8)$. 


\section{Discussion.}

The objective of this study was to compare kinematics of the gait cycle in health adults in four conditions and their combinations: forward walking, backward walking, dry land and in shallow water. We chose to quantify the forward and backward walking because these exercises are frequently used in rehabilitation and aquatherapy (10) and no previous studies have analyzed it exhaustively. The main finding of the present study indicates that for healthy adults there were a number of differences between walking on land and in water. Thus, kinematics variables were significantly associated with environment and direction.

According to the results, on land and at comfortable step frequency (adapted to the water environment), adults walked significantly more slowly during BW compared to FW, but in water this difference didn't exist which is coincident with previous results $(10,17)$. When we only analyzed the FW in both environments, we also found that on land the speed was greater than in water (9-12). Differences between modalities and environments can be explained by the water drag force, a lower apparent body weight, a lower comfort (due to instability) and less practice of BW than FW on land than in water $(12,17,18)$. For this reason, in general, people are more careful during BW where an increase of problems with balance and falls because of the lack of forward vision is probable $(17,19)$. In sum, the hydrodynamic resistance in shallow water is the prime responsible for the slow movements and for the instability in displacement although the hydrostatic pressure provides more security to exert its action on whole submerged body surface and avoid the risk of falls.

In most studies, data for step length are less numerous than for stride length. The observation that the subjects walked with a longer stride and step length on land than in shallow water at both directions (but not at BW in step length) $(9,11,26,27)$ and at FW than at BW at the same environment, is consistent with findings in the literature (18). In a gait cycle, we observed that the support phase duration decreases in water compared to land $(9,11)$. Probably this change is due to the buoyancy force of the water acting on the human body and the resulting increase of the swing phase duration, leaving the subjects with a shorter support phase in water. This result seemed much related to differences that we found between environments concerning stride length, speed, among others. 
As we previously reported for walking on land, the symmetry of step length and step time was an important measure providing information and insight about the control of walking. Our results on land confirm that, according to several authors $(13,28)$, healthy adults are highly symmetrical. Despite the growing use of the aquatic environment, no previous studies have analyzed the symmetry of this activity. In order to study the symmetry of step time and duration we controlled the frequency (adapted in shallow water as Masumoto et al. 2009 defined). As a result, we didn't find significant differences at the same environment. The profile of the step length symmetry was decrease (high value) in water compared with on land at FW and at BW. In this context, a slight asymmetry is considered within normal limits and may reflect functional differences in the contribution of each limb to propulsion and control during walking $(13,29)$. Additionally, the water resistance and the water movements generate greater instability causing less controlled movements and are responsible for the asymmetry. This finding provides interesting gait information in water and could have an important role in guiding clinical decisions, prescription and rehabilitation.

Qualitatively (see figure 6.1, 6.2 and 6.3) in the analysis of the joint angle, we observed that in the trajectory of the hip angle there was no coincidence between the angle degrees at the initial contact of the first cycle and at the final of it (coinciding with the initial contact of the second cycle). This occurred because at FW in water, as already mentioned; the subjects had no stability in terms of the position of the hip due to the water forces described beforehand.

At the initial contact, the angle of the ankle is more dorsi-flexed at BW on land than BW in shallow water. In addition, concerning the environment, BW results in a greater dorxi-flexion than FW on land. Other authors, also found differences between FW and BW but they didn't find significant differences between land and water (17). At final stance, BW was associated with more plantar flexion when subjects walked in water than on land and compared to the FW in water. Consistent with Kodesh et al., (2012) we observed that some participants lost the contact at the end of this phase because of a heel-off. Conversely, Carneiro et al. (2012) didn't show differences concerning the walking direction in either condition.

In spite of showing a similar waveform in FW and BW both in shallow water and land, we observed that the knee angle, at IC, was more flexed during FW in water than FW on land, but we didn't find differences at BW. These results are partially in agreement with the work of Carneiro et al. (2012), who reported that in BW it was more 
flexed in water compared to on land. At FS, consistent to Barela et al. (2008) and Carneiro et al. (2012), the knee was more flexed at FW than at BW, in both environments. Concerning the differences between water and land and looking at FW and $\mathrm{BW}$ taken together, these results can be justified by the adaptation of the movements in the water seeking to reduce the length of the body segments, and therefore the water resistance (to achieve greater efficiency in the movement).

In contrast to the profile of the knee angle, the hip angle showed a similar waveform only during the first $40 \%$ of the gait cycle in all modalities and conditions. Approximately during the remaining $60 \%$ the hip was more flexed in water than on land. At initial contact, the hip was more flexed at FW than at BW in water compared to land. In the same environment, FW was more flexed than BW. This is also agreed with the results of Carneiro et al. (2012) and in disagreement with Barela et al. (2008) who found the same degree of flexion in both environments. We considered that the main different in these results might also be related to the age of the participants (elderly subjects, more than 47 years difference). At FS, our results showed that the hip was more flexed in water than on land at both directions and at BW than at FW on land and in water as in to Barela et al. (2008) and Carneiro et al. (2012).

Finally, the mediolateral displacement (X axis), which stays constant on land, experiences an increase in water, which indicates the imbalance of the gait in the frontal plane. We have to take into consideration that when we make the movement without the support of our arms acting as equilibrators, the force of the water and the dragging of the body through the movement are the origins of this lateral displacement. On the $\mathrm{Z}$ axis, the displacement of the center of masses is likewise greater in water than on land when comparing the same movement.

The logical explanation lies in the action of the force of flotation which provokes the body to be pushed upward, not only reducing the time during which the feet are in contact but also provoking an increase of the elevation of the center of masses during the displacement. 


\section{Limitations and strengths of the study.}

The main limitations in our research are the analysis of one stride and the small simple size because it is possible that some small effects may not have been found. Nevertheless, this aspect does not affect the significant results. One of the strengths is the in depth study of kinematics variables in different conditions and directions. Also, the three dimensional motion analysis provides a more accurate description of walking.

\section{Conclusions.}

As a whole, the present study quantified many kinematics aspects of walking in water and compared them to walking on land. Specifically, confirming our hypothesis, the effect of the hydrodynamic resistance in shallow water conditioned the stride length and therefore, the speed in water was lower than on land. Also, the buoyancy force determined that a less support phase duration and a greater oscillation in $\mathrm{Z}$ axis of the center of mass of the hip. The hydrostatic pressure combined with the water drag could induce limb movement modifications and particularly angular variables. Regarding the center of mass, we observed that there was more instability in the mediolateral and vertical plane in water than on land.

Furthermore, this information provide a more precise point for the development of rehabilitation programs in water and on land for adults, detect problems with humans locomotion and may be used to therapists and clinicians to prescribe and select the correct treatment keeping in mind the adaptation of the exercises and the characteristics of the executions to the intervening forces in the water: resistance, flotation, pressure and propulsion. Future research required analyzing the current variables in pathological populations.

\section{Acknowledgements}

This work was supported by an initiation grant to research of University of Granada awarded to C.Cadenas. The authors wish to thank the CTS-527 research group members for their implication in this project. They also gratefully acknowledge the collaboration of all participating subjects. 


\section{Conflict of interest statement}

The authors of this study have no conflicts of interest to disclose.

\section{What is already known on this topic}

The most used rehabilitation strategies are walking forward and backward. Numerous exercises have been proposed in widely varying programs of rehabilitation, however further studies are needed to establish the information regarding the kinematics characteristics of walking in both environments.

\section{What this study adds}

At comfortable speed, the environment evokes changes in walking characteristics. Speed, stride and step length and support phase duration are greater on land than in water. Symmetry of step length was affected by the water resistance and the hydrostatic force. Also, the knee and hip angles was more flexed in water than on land. We observed more instability of the center of mass in water than on land. 


\section{References}

1. Hicheur H, Kadone H, Grèzes J, Berthoz A. The Combined Role of MotionRelated Cues and Upper Body Posture for the Expression of Emotions during Human Walking. In: Mombaur K, Berns K, editors. Modeling, Simulation and Optimization of Bipedal Walking. Cognitive Systems Monographs. 18: Springer Berlin Heidelberg; 2013. p. 71-85.

2. Schmid A, Duncan PW, Studenski S, Lai SM, Richards L, Perera S, et al. Improvements in speed-based gait classifications are meaningful. Stroke. 2007 Jul;38(7):2096-100. PubMed PMID: WOS:000247513300033.

3. Patterson KK, Nadkarni NK, Black SE, McIlroy WE. Gait symmetry and velocity differ in their relationship to age. Gait Posture. 2012 Apr;35(4):590-4. PubMed PMID: WOS:000303229300012.

4. Routson RL, Clark DJ, Bowden MG, Kautz SA, Neptune RR. The influence of locomotor rehabilitation on module quality and post-stroke hemiparetic walking performance. Gait Posture. 2013 (0).

5. Gordon CD, Wilks R, McCaw-Binns A. Effect of Aerobic Exercise (Walking) Training on Functional Status and Health-related Quality of Life in Chronic Stroke Survivors A Randomized Controlled Trial. Stroke. 2013 Apr;44(4):1179-81. PubMed PMID: WOS:000316673900054.

6. Cho KH, Lee WH. Virtual Walking Training Program Using a Real-world Video Recording for Patients with Chronic Stroke A Pilot Study. American Journal of Physical Medicine \& Rehabilitation. 2013 May;92(5):371-80. PubMed PMID: WOS:000317919600001.

7. Bohannon RW, Andrews AW, Smith MB. Rehabilitation goals of patietns with hemiplegia. Int J Rehabil Res. 1988;11(2):181-3. PubMed PMID: WOS:A1988R872800012. English.

8. Bowden MG, Embry AE, Perry LA, Duncan PW. Rehabilitation of Walking After Stroke. Curr Treat Options Neurol. 2012 Dec;14(6):521-30. PubMed PMID: WOS:000311200400002. English.

9. Orselli MIV, Duarte M. Joint forces and torques when walking in shallow water. J Biomech. 2011 Apr;44(6):1170-5. PubMed PMID: WOS:000290187500028. English. 
10. Chevutschi A, Alberty M, Lensel G, Pardessus V, Thevenon A. Comparison of maximal and spontaneous speeds during walking on dry land and water. Gait Posture. 2009 Apr;29(3):403-7. PubMed PMID: WOS:000264469300009. English.

11. Barela AMF, Duarte M. Biomechanical characteristics of elderly individuals walking on land and in water. J Electromyogr Kinesiol. 2008 Jun;18(3):446-54. PubMed PMID: WOS:000256600400011. English.

12. Barela AMF, Stolf SF, Duarte M. Biomechanical characteristics of adults walking in shallow water and on land. J Electromyogr Kinesiol. 2006 Jun;16(3):250-6. PubMed PMID: WOS:000237996800004. English.

13. Kodesh E, Kafri M, Dar G, Dickstein R. Walking speed, unilateral leg loading, and step symmetry in young adults. Gait Posture. 2012 Jan;35(1):66-9. PubMed PMID: WOS:000300267400012.

14. Kim CM, Eng JJ. Symmetry in vertical ground reaction force is accompanied by symmetry in temporal but not distance variables of gait in persons with stroke. Gait Posture. 2003 Aug;18(1):23-8. PubMed PMID: WOS:000184403800003.

15. Volaklis KA, Spassis AT, Tokmakidis SP. Land versus water exercise in patients with coronary artery disease: effects on body composition, blood lipids, and physical fitness. American Heart Journal. 2007 Sep;154(3). PubMed PMID: WOS:000249390100026.

16. Tsourlou T, Benik A, Dipla K, Zafeiridis A, Kellis S. The effects of a twentyfour-week aquatic training program on muscular strength performance in healthy elderly women. Journal of Strength and Conditioning Research. 2006 Nov;20(4):811-8. PubMed PMID: WOS:000242414300014.

17. Carneiro L, Michaelsen SM, Roesler H, Haupenthal A, Hubert M, Mallmann E. Vertical reaction forces and kinematics of backward walking underwater. Gait Posture. 2012 2//;35(2):225-30.

18. Masumoto K, Hamada A, Tomonaga HO, Kodama K, Amamoto Y, Nishizaki Y, et al. Physiological and perceptual responses to backward and forward treadmill walking in water. Gait Posture. 2009 Feb;29(2):199-203. PubMed PMID: WOS:000263506900005. English.

19. Masumoto K, Takasugi SI, Hotta N, Fujishima K, Iwamoto Y. A comparison of muscle activity and heart rate response during backward and forward walking on an underwater treadmill. Gait Posture. 2007 Feb;25(2):222-8. PubMed PMID: WOS:000244102200010. English. 
20. Kim YS, Park J, Shim JK. Effects of Aquatic Backward Locomotion Exercise and Progressive Resistance Exercise on Lumbar Extension Strength in Patients Who Have Undergone Lumbar Diskectomy. Archives of Physical Medicine and Rehabilitation. 2010 Feb;91(2):208-14. PubMed PMID: WOS:000277417600008.

21. Kachanathu SJ, Hafez AR, Zakaria AR. Efficacy of backward versus forward walking on hamstring strain rehabilitation. IJTRR. 2013;2(1):8-14.

22. Patterson KK, Gage WH, Brooks D, Black SE, McIlroy WE. Evaluation of gait symmetry after stroke: A comparison of current methods and recommendations for standardization. Gait Posture. 2010 Feb;31(2):241-6. PubMed PMID: WOS:000274584800018.

23. Grasso R, Bianchi L, Lacquaniti F. Motor patterns for human gait: Backward versus forward locomotion. Journal of Neurophysiology. 1998 Oct;80(4):1868-85. PubMed PMID: WOS:000076487400022.

24. Kwon YH, Casebolt JB. Effects of light refraction on the accuracy of camera calibration and reconstruction in underwater motion analysis. Sports biomechanics / International Society of Biomechanics in Sports. 2006 2006-Jul;5(2):315-40. PubMed PMID: MEDLINE:16939159.

25. Kwon YH. Object plane deformation due to refraction in two-dimensional underwater motion analysis. Journal of Applied Biomechanics. 1999 Nov;15(4):396403. PubMed PMID: WOS:000083580100005.

26. Masumoto K, Shono T, Hotta N, Fujishima K. Muscle activation, cardiorespiratory response, and rating of perceived exertion in older subjects while walking in water and on dry land. J Electromyogr Kinesiol. 2008 8//;18(4):581-90.

27. Masumoto K, Hamada A, Tomonaga H, Kodama K, Hotta N. Physiological Responses, Rating of Perceived Exertion, and Stride Characteristics During Walking on Dry Land and Walking in Water, Both With and Without a Water Current. Journal of Sport Rehabilitation. 2012 May;21(2):175-81. PubMed PMID: WOS:000303627000012. English.

28. Lythgo N, Wilson C, Galea M. Basic gait and symmetry measures for primary school-aged children and young adults. II: Walking at slow, free and fast speed. Gait Posture. 2011 Jan;33(1):29-35. PubMed PMID: WOS:000287561100006. English.

29. Sadeghi H, Allard P, Prince F, Labelle H. Symmetry and limb dominance in able-bodied gait: a review. Gait Posture. 2000 Sep;12(1):34-45. PubMed PMID: 10996295. Epub 2000/09/21. eng. 